\title{
Exploration of the hydraulic structure of the water supply facilities operation mode and flow
}

\author{
Sanatjon Khidirov ${ }^{1}{ }^{*}$, Rustam Oymatov ${ }^{1}$, Bakhodir Norkulov $^{2}$, Furqat Musulmanov $^{3}$, Iroda \\ Rayimova $^{1}$, and Ikboloy Raimova ${ }^{1}$ \\ ${ }^{1}$ Tashkent Institute of Irrigation and Agricultural Mechanization Engineers, Tashkent, \\ Uzbekistan \\ ${ }^{2}$ Samarkand State Architectural and Civil Engineering Institute, Samarkand, Uzbekistan \\ ${ }^{3}$ Bukhara Branch of the Tashkent Institute of Irrigation and Agricultural Mechanization \\ Engineers, Bukhara, Uzbekistan
}

\begin{abstract}
For multi-section drainage facilities, it is important to develop operational measures based on maneuvering moving barriers. Maneuvering of moving barriers is a measure that carries out the flow of water from the upper reaches to the lower reaches at the required level, taking into accounts the design features and operational mode of the hydraulic regime of the drainage structure. The maneuvering mode in the flow of water from the discharge structures ensures the order of opening, phasing, and level of opening of these movable barriers. Hydraulic conditions are associated with the effective control of the hydraulic regime in the lower part of the drainage structure or the suppression of excess kinetic energy, the reversal of the flow, or the prevention of post-riser deformation processes. Creating conditions ensuring that the hydrotechnical and hydropower construction of the water transfer or discharge facility is adapted for use in conjunction with a hydropower plant, water intake, sluices, and flow control system.
\end{abstract}

\section{Introduction}

At present, it is especially important to conduct targeted research aimed at the development of scientifically based calculation methods for quenching the kinetic energy of water flow in water discharge facilities, the selection of flow energy quenching structures, the elimination of water flow inversion [1-6]. In this regard, it is important to determine the relative magnitudes of the calculated dynamics of the critical parameters of the flow in the drainage facilities, the location of water flow energy extinguishers, and the development of design solutions. At the same time, one of the important tasks is to select design solutions for quenching the kinetic energy of water flow in water discharge facilities, to determine the hydrodynamic stresses of water flow to lower basin structures, to conduct new experimental research on water connection and discharge structures and to conduct scientifically based calculation methods [7-14].

In this regard, the water reservoirs of water to remove the bottom of the facilities befit the structure of the soil structure, taking into account the flow of water and energy and

\footnotetext{
*Corresponding author: sanat.kx@gmail.com
} 
small distances, repayment of the fall of the water flow the application of measures to prevent abuse, the level of reliability and lifetime of the structure of the building had major improvements in dissipation energy designs today is one of the important functions.

\section{Methods}

In the practice of operation of existing hydraulic and hydropower facilities, although the drainage facilities have a relatively simple design, their physical modeling is carried out on a large scale due to the high level of reliability of the structure $[1,2]$.

The water flow has a free surface on which gravity and friction forces play an important role. When building an experimental device, its compactness and small size make it cheaper. However, its shrinkage increases the effect of surface tension and friction forces on the water flow movement. In order to overcome this problem, it is required that the scale coefficient be 50-60, the value of the coefficient of flow rate in the water pipe be less than $5 \%$, the water flow rate is higher than $6.5 \mathrm{~mm}$, and the smoothness of the surfaces on which the water flows. Experimental laboratory studies conducted under these conditions provide accurate results for practice when water flows through a culvert from a discharge facility [3, 4]. In the physical modeling of hydraulic phenomena, it is expedient to fulfill the conditions of geometric similarity, the similarity of initial and boundary conditions, dynamic and kinematic similarity laws corresponding to the forces involved in the formation of the flow [15-18].

\section{Results and Discussion}

Numerous experimental and theoretical studies conducted by the researchers have come to the following general conclusions on the basis of the process of external hydraulic jump at the pound connection [19-23]:

- it is recommended that the drainage facilities, which will be connected to the surface in the form of external hydraulic jumps, be constructed in places where the riverbed consists of unwashed rocks;

- It can be constructed even for non-rocky dams where the pound joints are sufficiently calculated, and the lower pound reinforcement structures have a high degree of reliability, even in the appearance of a hydraulic jump.

At the same time, the shortcomings of the dams, where the connection of the pounds of this type takes place, have also been identified. One of the main drawbacks is that the appearance of the hydraulic jump consists of several types, the flow in the lower part of the structure changes the depth in a very small range, and it is recognized that all types of external hydraulic jumps occur in this range. The following main conclusions were drawn:

- several manifestations of the combined hydraulic jump occur at the bef connection, and the efficiency is much lower than at the bef connection at the bottom of the stream;

- in the form of an external hydraulic jump, the length of the contact area is longer than when descending along the bottom of the channel when the pounds are connected, and the excess kinetic energy is more attenuated at the connection along the bottom of the channel;

- the water level oscillations when the bays are connected in the form of external hydraulic jumps are much higher than when connected to the bottom of the basin, resulting in reduced energy production efficiency in hydropower plants and increased coastal washing intensity in the lower bays;

- the efficiency of power extinguishers built in the lower reaches of the drainage system is low, and the implementation of external connection in the form of external 
hydraulic jumps reduces the operating mode and does not give the expected result in operation [5-8].

By analyzing the hydraulic regimes of the structural elements and forms of the external pound connection in the form of an external hydraulic jump, we selected the following options for experimental studies:

We are researching a water disposal facility with a multi-section practical profile water pipe. In this construction, we study the hydraulic parameters and dynamics of the flow state at different water flows of the flow. We named the study series ES №1 (Figure 1).

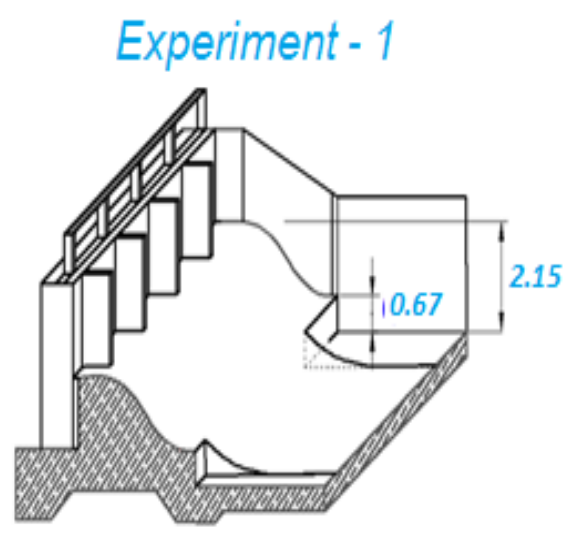

Fig. 1. The ES-1 series is a drainage facility where experimental studies have been conducted.

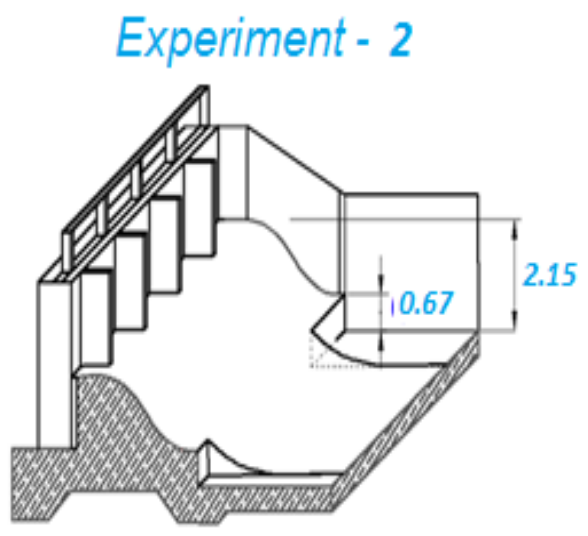

Fig. 2. The ES-2 series is a drainage facility where experimental studies have been conducted.

In our next phase of research, energy quenching with wall-to-wall barriers in the movement of water flow was carried out along the drainage structure. In this case, depending on the size and location of the barrier walls, the dynamics of movement of the water flow in the short channel and the dynamics of extinction in the field, and the area of excess kinetic energy to the pounds junction were studied. We named the study series ES №2 (Figure 2).

In determining the size of the structural elements in the study, we used the results of the work of scientists who conducted field, laboratory, and theoretical research in this area [913]. A detailed analysis of the recognized studies provided an opportunity to determine the relative height $\frac{c}{h}=0.67$ or $\frac{c}{P}=0.31$ as of the barrier wall in the final area of the structure. Where: $c$ is the height of the barrier wall; $h$ is the critical depth of flow; $P$ is the height of the platform from the roof of the lower pound.

The view of the connection area at the bottom of the drainage structure was adopted according to the following schemes.

At the beginning of the study, the kinematic structure of the flow and the range of variation of the motion modes at different values of the calculated consumption were studied in all variant studies. A characteristic feature of this study is that during the studies, it was ensured that the connection of the pounds in the appearance of the hydraulic jump is formed not by adjustment by the lower pound but by the actual operating conditions of the structure. In this case, the direction of research was determined mainly by the dynamics of the Froude number and the kinetic parameters of the flow, the dynamics of the calculated consumption, the calculated relative magnitudes of the structural elements [24-39].

In the study of comparable options, the range of calculated costs, the parameters characterizing the flow mode, and the hydraulic parameters of the flow were also measured in the lower basin. Velocities were always measured vertically in the selected storks. Visual, photo and video observations were performed in conjunction with hydrometric 
measurements. In the study, changes in the kinematic structure of the flow were observed in detail, using colors whose density was the same as the density of water at the top of each gate. In the study, flow transformation was observed in photo and video plates [14]. Figure 3 shows the characteristic views of the flow motion.
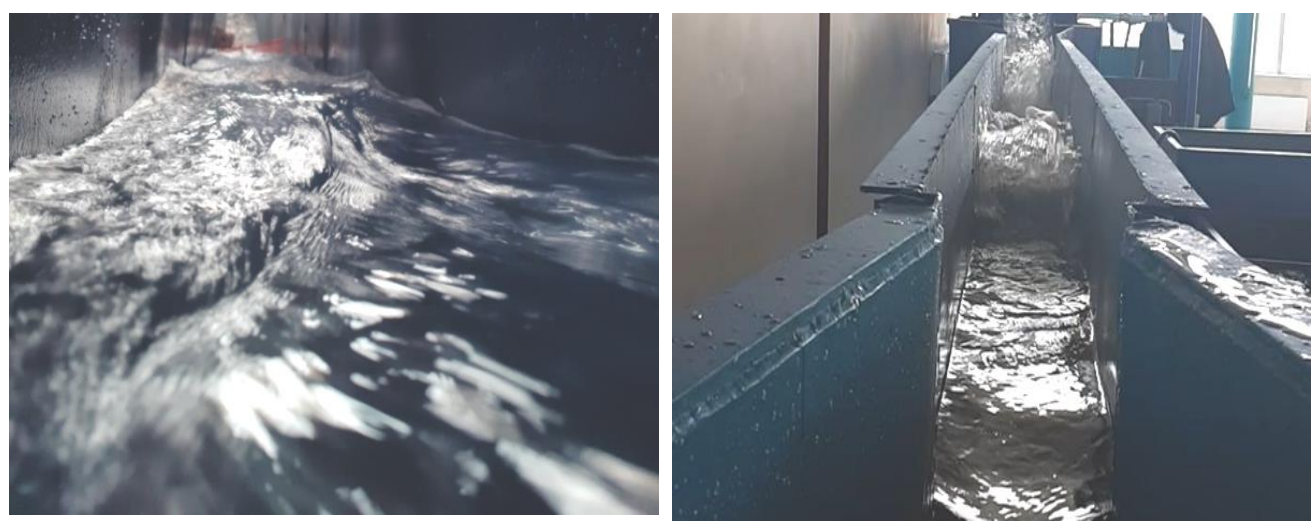

Fig. 3. Views of flow motion in the experimental model.

When studying hydraulic regimes, the following parameters of the flow from the discharge structures for natural conditions were studied:

- water consumption $Q=3,9 \div 18.6 \mathrm{l} / \mathrm{s}$;

- average flow rate $v=15 \div 150 \mathrm{~cm} / \mathrm{s}$;

- the average depths in the lower pound are $h=8 \div 21 \mathrm{~cm}$.

- the relative variability range of these modes was taken as follows:

- $\quad$ specific costs $K_{Q}=\frac{Q}{Q_{p}}=0,06 \div 0,53$ where: $Q$ and $Q_{p}$ are current and estimated costs;

- the utilization coefficient of $\beta=\frac{b}{B}=0,35 \div 0,583$ the water front, is where: $b$ is the width of the working sections, $B$ is the width of the lower pound;

The range of defined flow parameters allows us to determine the limits of application of the laws identified in our research.

Under the conditions of operation of multi-section drainage facilities on real objects, the flow movement will have a spatial character. In this respect, research differs from flat case studies. Under such conditions, there is no asymmetry in the distribution of specific costs. This situation requires the prediction of the dynamics of the pressure and depth, the maneuverability of the barriers, and the consumption of water discharged during the operation of hydraulic structures. The operation to remove the water, the resulting data structures symmetrical flow distribution of the collapse of its turnover and downstream, allowing for the formation of water in the background and depth of deformation $\mathrm{r}$ learning to give $\mathrm{y}$. Therefore, maneuvering schemes that lead to a state of symmetrical distribution of specific consumption during operation are widely used. In the dissertation work, taking into account this situation, the hydraulic regimes of the flow in the symmetrical maneuvering process were studied [15-18].

Considering the above, 5 views of the most widely used maneuvering schemes for the symmetrical flow of water in drainage facilities were adopted. A table of these schemes is given in Table 1. 
Table 1. Maneuvering schemes of moving barriers of drainage structures

\begin{tabular}{|c|c|c|c|c|}
\hline № & $\begin{array}{c}\text { Water } \\
\text { consumption } \\
\mathrm{Q}, l / s\end{array}$ & $\begin{array}{c}\text { Comparative } \\
\text { spending } \\
K_{Q}\end{array}$ & $\begin{array}{c}\text { Coefficient of } \\
\text { utilization of the } \\
\text { water front, } \mathrm{b}\end{array}$ & $\begin{array}{c}\text { № Section number of } \\
\text { open sections }\end{array}$ \\
\hline 1 & 3.90 & 0.06 & 0.35 & $2 ; 4$ \\
\hline 2 & 6.90 & 0.185 & 0.35 & 3 \\
\hline 3 & 10.07 & 0.296 & 0.47 & $1 ; 3 ; 5$ \\
\hline 4 & 11.60 & 0.42 & 0.47 & $2 ; 4$ \\
\hline 5 & 13.87 & 0.53 & 0.583 & $2 ; 4$ \\
\hline
\end{tabular}

The current movement of water in the characteristic forms of 4 to 8 - figures expressed.

The comparable options work the same in the observed studies when the flow rate from 2,4 order numerical units at values of water consumption $Q=3.90 \mathrm{l} / \mathrm{s}\left(K_{Q}=0.06 ; \beta=0.35\right)$ (Fig. 4). The reason for this can be justified by:
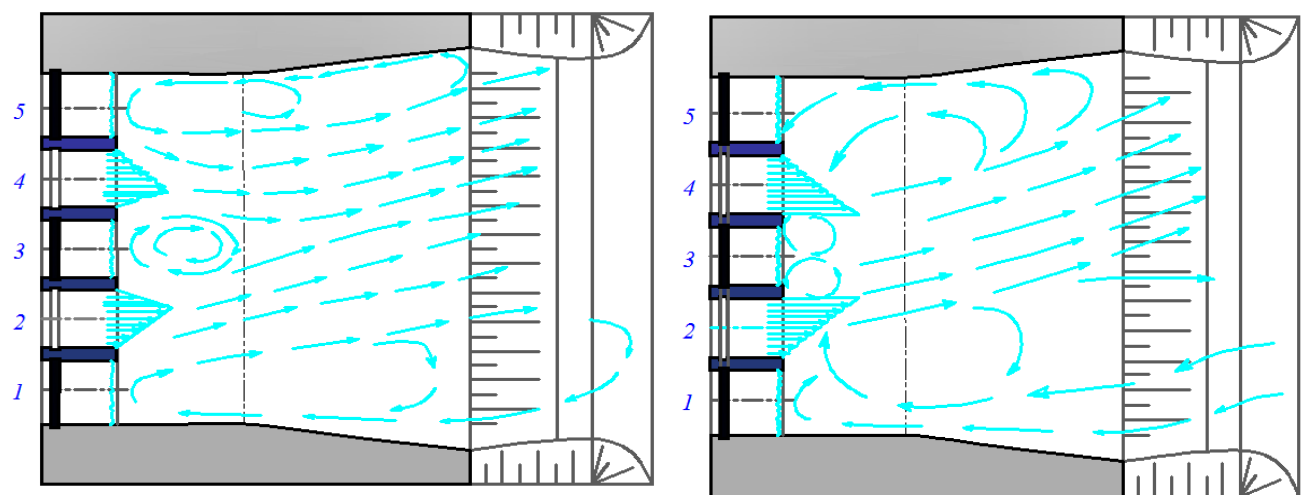

Fig. 4. In studies on the first option, water flow movement at values of consumption $Q=3.90 \mathrm{l} / \mathrm{s}$.

In the case of a drainage structure, the connection with the river's surface is carried out in the main view. The flow from the barrier installed at the end of the downstream drainage structure takes on the appearance of a single transit stream and occupies half the width of the channel. The formation of water cycles was observed on the coastal side. The water circulation affected the movement of the transit stream, causing it to spread across the reinforcement area. The maximum values of the reverse velocities of the water cycles were of a magnitude comparable to the values of the transit flow velocities. The maximum velocity of the reverse currents in the apron area was 50-55\% smaller than the maximum velocity of the transit flow.

When the water flow was $\mathrm{Q}=6.9 \mathrm{l} / \mathrm{s}\left(K_{Q}=0.185 ; \beta=0.35\right)$ and № 3 compartment was open (Figure 5), a bubble-shaped hydraulic jump occurred in the water injection well, burying the middle walls at the edge. The propagation of the stream was symmetrical because it was a single section, relatively wide when it came to apron. Strong water cycles formed on both sides of the Ort. These rotations began to squeeze the transit flow from both sides. The maximum velocity of transit flow was $76 \div 86 \%$ of the maximum velocity of water circulation. Analysis of the vertical position of the velocity distribution showed that the underwater connection of the pounde occurs in both study variants. The lower pounde of the structure re-formed the vertical velocity diagrams in the Lieberman area and took on the appearance of diagram in the external connection mode. 

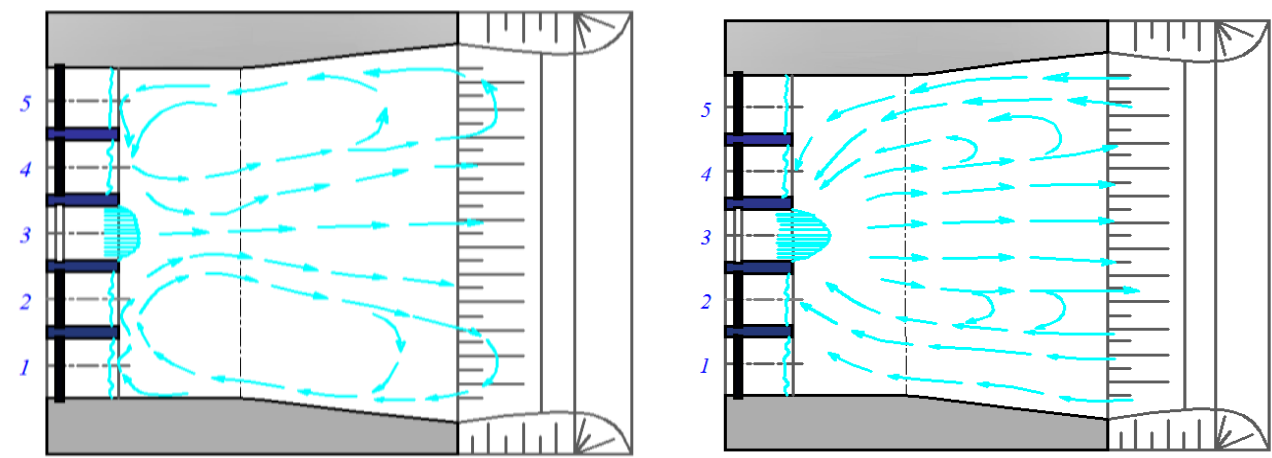

Fig. 5. Movement of water flow in the lower basin $(Q=6.9 \mathrm{l} / \mathrm{s})$.

In the mode corresponding to these parameters $Q=10.07 \mathrm{l} / \mathrm{s}\left(K_{Q}=0.296 ; \beta=0.47\right)$ water was discharged through one of the following sections № 1; 3; 5 (Figure 6). In the first of the studied options, the water level operated in the mode of smooth contact with the water impact wall, while in the second option, the water level exceeded it in the presence of obstacles. In this case, the main streams moved along the walls of the section, and the stream moving in the center was constantly changing its direction. The small water cycles formed were pushed towards the closed sections, while the large water circulation was pushed towards the apron and merged with the main flow in this area. In the first variant studies, the distribution of the flow along the width of the channel was of a flat nature, whereas the analysis of velocity distribution diagrams showed that there was a connection along the surface of the channel, in the second option, there was a combination of surface and combined bottom.

During our experiments, a two-by-one mixed scheme was used in the parameters $Q$ $=11.6 \mathrm{l} / \mathrm{s}\left(K_{Q}=0.42 ; \beta=0.47\right)$. That is, № Sections $2 ; 4$ (Figure 7) were open. For these schemes, in the first option, there was a barrier in one and not in the second. In both variants, water circulation nuclei were formed, and flow propagation was observed. The water on the right bank was smaller than the left bank in terms of circulation scale and was pushed in the reinforcement area; the water circulation on the right bank was larger, compressing and deforming the transit flow, and was observed to shift to the left relative to the river axis.
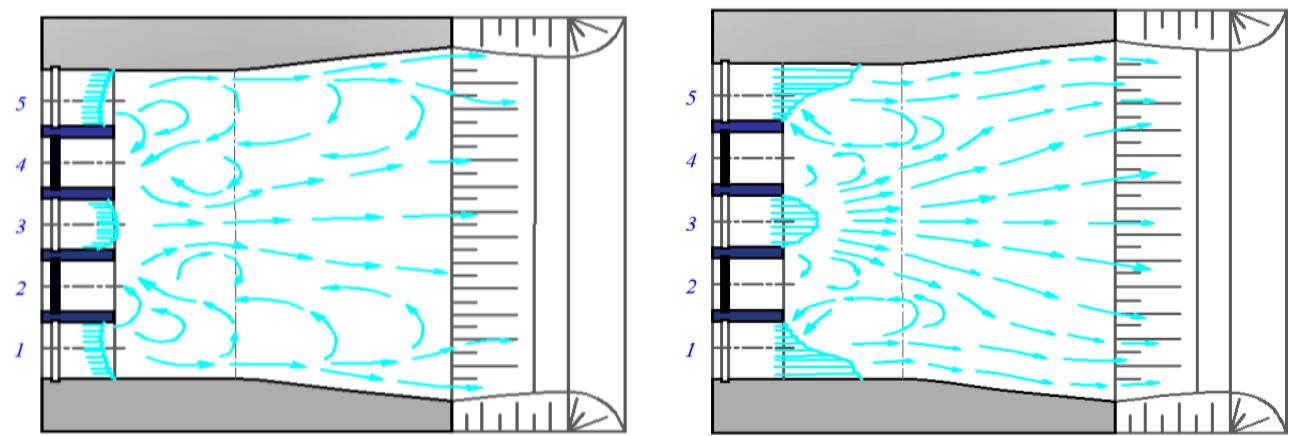

Fig. 6. Reimbursement $\mathrm{Q}=10.076 \mathrm{l} / \mathrm{s}$ hit the water to remove the water of the dam facility in the field of breast flow plan view. 

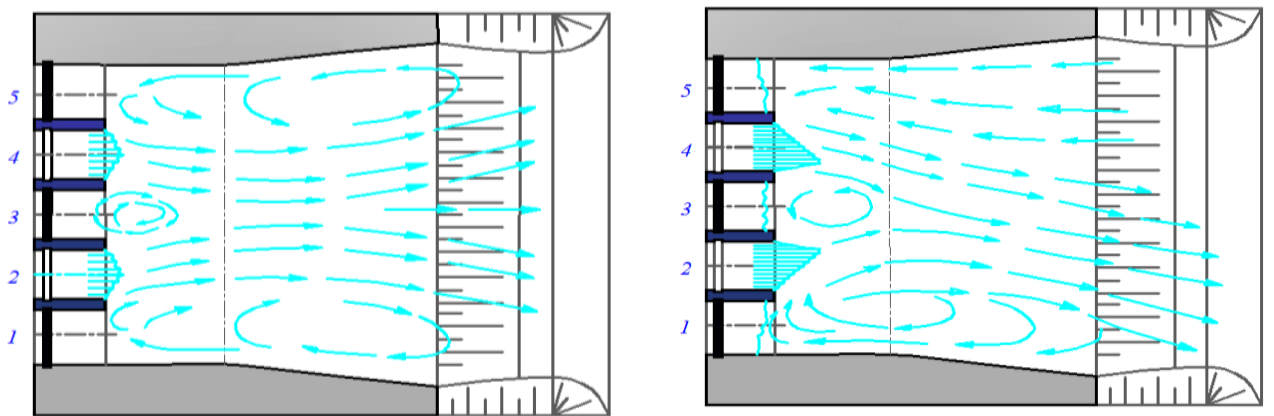

Fig. 7. $Q=11.6 \mathrm{l} / \mathrm{s}$ supplies the water to remove the dam construction in the field of water facility and spread flow plan view.

The difference between water circulation and transit flow rates was $50-70 \%$, and the flow rate in apron decreased to $9 \div 13 \%$. The flow began to flow from the unobstructed sections and closed sections into the transit stream that flowed through the barriers. The currents were compressed under the influence of flow masses coming from above, leading to an increase in the average velocity near the bottom of the stream.

According to the mixed scheme of flow rate $\mathrm{Q}=13.87 \mathrm{l} / \mathrm{s}\left(K_{Q}=0.53, \beta=0,583\right)$, № 2; 4 (Figure 8) transit flow was observed along the intermediate walls and in the area of the five sections along the stream. A smaller water cycle in geometric size was observed in the right bank retaining wall area, and a larger water cycle up to the reinforcement area was formed in the left bank.
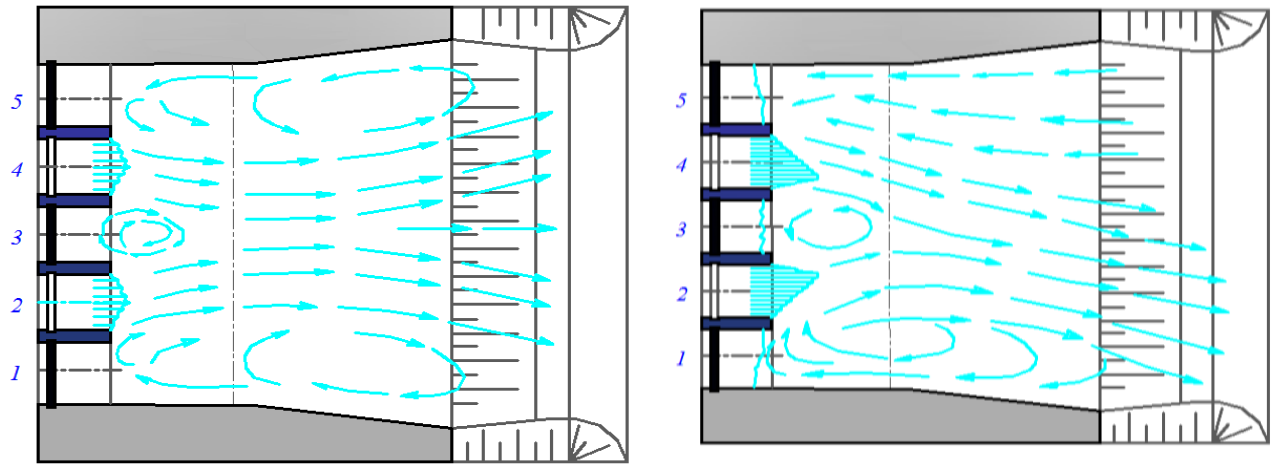

Fig. 8. Trajectory of water flow through the sections of the drainage structure according to the mixed scheme

It was observed that its dynamic axis is curved due to the large water circulation effect on the transit flow. The average velocity of water flowing along the bottom of the river was $31 \div 62 \%$ higher in the first variant and $44 \div 73 \%$ higher in the second variant than the surface velocity. The velocities distribution diagrams in the verticals were rhythmic. The connection mode in this circuit was close to the connection along the surface of the stream.

\section{Conclusions}

With the increase in water consumption and water use front coefficients, the distribution of specific flow and flow velocity along the channel width and flow depth improves. Also, the hydraulic-kinematic structure of the flow is improved in symmetrical water discharge; 
In the first variant study using a single-section intermittent barrier, almost all water consumption values used in the study showed low flow overflow at the bottom of the hydraulic structure, the relationship of water circulation with the transit flow, low flow capacity, ie, good hydraulic regime. When barriers were installed in each section, it was recognized that the specific cost in the field of reinforcement of the structure was $7 \div 45 \%$ higher than in the first study option. It should be noted that in the first variant studies, the speed of movement along the subsurface area decreased;

An increase in transit flow velocity was observed in both variant studies in reinforcement of the lower part of the structure when water was discharged from the open section after side sections in the drainage structures. One section of the multi-section dewatering facility was closed. The other was open, and at all consumption values accepted in the study, the pounde connection was performed in a more favorable manner than in the first case.

\section{References}

1. Khidirov, S., Norkulov, B., Ishankulov, Z., Nurmatov, P., Gayur, A. Linked pools culverts facilities. IOP Conf. Ser. Mater. Sci. Eng., 883(1), 012004 (2020)

2. Bazarov D., Vatin N., Obidov B., and Vokhidov O. Hydrodynamic effects of the flow on the slab of the stand in the presence of cavitation. IOP Conf. Ser. Mater. Sci. Eng. 1030, 012110 (2021).

3. Krutov A., Choriev R., Norkulov B., Mavlyanova D. and Shomurodov A. Mathematical modelling of bottom deformations in the kinematic wave approximation. IOP Conf. Ser. Mater. Sci. Eng. 1030, 012147 (2021).

4. Bazarov D., Markova I., Norkulov B. and Vokhidov O. Hydraulic aspects of the layout of head structures during water intake from lowland rivers. IOP Conf. Ser. Mater. Sci. Eng. 1015, 012041 (2021).

5. Uralov B., Rakhmatov N., Khidirov S., Uljaev F., Raimova I. Hydraulic modes of damless water intake. IOP Conf. Ser. Mater. Sci. Eng. 1030(1), 012123 (2021)

6. Uralov, B., Khidirov, S., Artykbekova, F., Shodiev, B. Influence of the roughness and shape of the canal of trapezoidal canals on the pressure loss of hydropower structures. Lecture Notes in Civil Engineering, 141, pp. 35-46, (2021)

7. Krutov A., Norkulov B., Uljaev F., and Jamalov F. Results of a numerical study of currents in the vicinity of a damless water intake. IOP Conf. Ser. Mater. Sci. Eng. 1030, 012121 (2021).

8. Bazarov D., Markova I., Sultanov S. and Kattakulov F. Dynamics of the hydraulic and alluvial regime of the lower reaches of the Amudarya after the commissioning of the Takhiatash and Tuyamuyun hydrosystems. IOP Conf. Ser. Mater. Sci. Eng. 1030, 012110 (2021).

9. Khidirov S., Jumaboeva G., Ishankulov Z., Nishanbaev K., Egamberdieva S. Hydraulic mode of operation of the Takhiatash hydroelectric complex, IOP Conference Series: Materials Science and Engineering, 1030 (1), 012120, (2021)

10. Krutov A., Norkulov B., Mavlyanova D. Simulation of spreading of non-conservative passive substances in water bodies. IOP Conf. Ser. Mater. Sci. Eng. 883(1), 012028 (2020) 
11. Bazarov D. and Vokhidov O. Extinguishing Excess Flow Energy in Spillway Structures. In book: Proceedings of EECE 2020, LNCE 150, pp. 535-545, (2021) DOI: 10.1007/978-3-030-72404-7_52

12. Bazarov D., Markova I., Norkulov B., Isabaev K., Sapaeva M. Operational efficiency of water damless intake. IOP Conf. Ser. Mater. Sci. Eng. 869(7), 072051, (2020)

13. Matyakubov B., Begmatov I., Raimova I. and Teplova G. Factors for the efficient use of water distribution facilities. IOP Conf. Ser. Mater. Sci. Eng. 883, 012025 (2020).

14. Obidov B., Vokhidov O., Tadjieva D., Kurbanova, U., Isakov A. Hydrodynamic effects on the flow elements of the downstream devices in the presence of cavitation. IOP Conf. Ser. Mater. Sci. Eng. 1030, 012114 (2021).

15. Bazarov D., Norkulov B., Vokhidov O., Uljaev F., Ishankulov, Z. Two-dimensional flow movement in the area of protective regulatory structures. IOP Conf. Ser. Mater. Sci. Eng. 890, 012162 (2020)

16. Krutov A., Norkulov B., Nurmatov P., Mirzaev M. Applicability of zero-dimensional equations to forecast nonconservative components concentration in water bodies. IOP Conf. Ser. Mater. Sci. Eng. 883(1), 012028 (2020)

17. Zare, H.K., Doering, J.C.: Effect of rounding edges of stepped spillways on the flow characteristics. Can. J. Civ. Eng. 39, 140-153 (2012). https://doi.org/10.1139/L11121.

18. Zong, Q., Liu, H., Tang, H.: Study on effect of spillway trough on spillway crest length of sand basin. In: 2009 International Conference on Information Management, Innovation Management and Industrial Engineering, ICIII 2009. pp. 98-101 (2009). https://doi.org/10.1109/ICIII.2009.182.

19. Pereira, G.M., Pereira, G.M.: Spillway design. In: Spillway Design - Step by Step. pp. 73-124 (2020). https://doi.org/10.1201/9780367816902-3.

20. Hunt, S.L., Kadavy, K.C.: Inception point for embankment dam stepped spillways. J. Hydraul. Eng. 139, 60-64 (2013). https://doi.org/10.1061/(ASCE)HY.19437900.0000644.

21. Eshev S., Latipov S., Qurbonov A., Berdiev M., Mamatov N. Non-eroding speed of water flow of channels running in cohesive soils. IOP Conf. Ser. Mater. Sci. Eng. 1030, 012131 (2021).

22. Shokirov B., Norkulov B., Nishanbaev Kh., Khurazbaev M., Nazarov B. Computer simulation of channel processes. E3S Web of Conferences, 97, 05012, (2019)

23. Eshev S., Rakhimov A., Gayimnazarov I., Shodiev B., Bobomurodov F. Dynamically stable sections of large soil canals taking into account wind waves. IOP Conf. Ser. Mater. Sci. Eng. 1030, 012134 (2021).

24. Shomayramov, M., Norkulov B., Rakhmanov J., Tadjiyeva D., Suyunov J. Experimental researches of hydraulic vacuum breakdown devices of siphon outlets of pumping stations. E3S Web of Conferences, 97, 05009, (2019)

25. Yangiev A., Eshev S., Panjiev S., Rakhimov A. Calculation of sediment flow in channels taking into account passing and counter wind waves. IOP Conf. Ser. Mater. Sci. Eng., 883, 012036 (2020)

26. Eshev S.S., Khazratov A.N., Rahimov A.R., Latipov S.A. Influence of wind waves on the flow in flowing reservoirs. IIUM Engineering Journal, 21(2), pp. 125-132, (2020)

27. Bazarov D., Markova I., Raimova I., Sultanov Sh. Water flow motion in the vehicle of main channels. IOP Conf. Ser. Mater. Sci. Eng. 883, 012025 (2020). 
28. Gur'ev,A.P., Kozlov D.V., Khanov N.V., Abidov M.M., Safonova N.A. Alternative Solutions for the Energy Dissipation of Idle Discharges at the Rogun HPP, Power Technology and Engineering, 2020, 54(1), pp. 7-12

29. Baranov E.V., Gur'yev A.P., Khanov N.V. Recommendations for Hydraulic Calculations of Anti-Erosion Lining with the Use of Spatial Geogrid with Coarse Fragmental Soil, Power Technology and Engineering, 2020, 53(5), pp. 553-556

30. Khanov N.V., Martynov D.Y., Novichenko A.I., Lagutina N.V., Rodionova S.M. Outlook and Special Properties of Earth Anchors and Screw Piles in Burial of Modular Protection Dikes in Nonrocky Ground, Power Technology and Engineering, 2018, 52(4), pp. 405-412

31. Kurbanov S.O., Khanov N.V. To calculation of the critical depths of the canals with polygonal profile (РР)б Gidrotekhnicheskoe Stroitel'stvo, 2004, (3), pp. 42-44

32. Kurbanov S.O., Khanov N.V. To hydraulic calculation of the most favorable sections of the power diversion canals (PDC) of a polygonal profile, Gidrotekhnicheskoe Stroitel'stvo, 2003, (7), pp. 40-43

33. Khanov N.V. Hydraulic characteristics of chamber-free tangential vortex flow generators, Hydrotechnical Construction, 1999, 33(2), pp. 99-103

34. Anghesom A. Ghebrehiwot, Kozlov D.V. Spatial and Statistical Variability Analyses of Satellite-Based Climatic Data in Mereb-Gash Basin, Water Resources, 48(1), pp. 146-157, (2021)

35. Bednaruk S.E., Chukanov V.V., Klenov E.M., Kozlov D.V. Accounting for the Thermal State of the Sayano-Shushenskaya Dam to Determine the Safe Maximum Water Levels in the Reservoir in Developing Its Dispatch Schedules, Power Technology and Engineering, 54(4), pp. 451-455, (2020)

36. Kozlov D., Yurchenko A. The role of inspection of hydraulic structures in the assessment of their technical condition, IOP Conference Series: Materials Science and Engineering, 883(1), 012049, (2020)

37. Kozlov D., Ghebrehiwot A. Integrated design and construction approach to hydrotechnical structures in Eritrea, IOP Conference Series: Materials Science and Engineering, 869(7), 072012, (2020)

38. Kozlov D.V., Kuleshov S.L. Multidimensional Data Analysis in the Assessment of Ice-Jam Formation in River Basins

39. Water Resources, 46(2), pp. 152-159, (2019) 